OPEN ACCESS

Edited by:

Ricardo González,

Kinder- und Jugendkrankenhaus Auf

der Bult, Germany

Reviewed by:

Peter Vajda,

University of Pécs, Hungary

Imran Mushtaq

Great Ormond Street Hospital,

United Kingdom

*Correspondence:

Martin Promm

martin.promm@

barmherzige-regensburg.de

Specialty section:

This article was submitted to

Pediatric Urology

a section of the journal

Frontiers in Pediatrics

Received: 14 December 2018

Accepted: 06 March 2019

Published: 29 March 2019

Citation:

Promm M and Roesch WH (2019) Recent Trends in the Management of Bladder Exstrophy: The Gordian Knot

Has Not Yet Been Cut.

Front. Pediatr. 7:110

doi: 10.3389/fped.2019.00110

\section{Recent Trends in the Management of Bladder Exstrophy: The Gordian Knot Has Not Yet Been Cut}

\author{
Martin Promm* and Wolfgang H. Roesch \\ Department of Pediatric Urology, Clinic St. Hedwig, University Medical Center of Regensburg, Regensburg, Germany
}

Although enormous effort has been made to further improve the operative techniques worldwide, the management of bladder exstrophy (BE) remains one of the most significant challenges in pediatric urology. Today it is universally agreed that successful and gentle initial bladder closure is decisive for favorable long-term outcome with regard to bladder capacity, renal function and continence. Due to a number of reasons, including a lack of comparable multicenter studies, a range of concepts is currently used to achieve successful primary closure. We review the literature of the last 15 years on the current concepts of bladder exstrophy repair with regard to the time of primary closure (initial vs. delayed closure), the concepts of primary closure (single-stage vs. staged approach; without osteotomy vs. osteotomy) and their outcomes. There is a worldwide lack of multicenter outcome studies with adequate patient numbers and precisely defined outcome parameters, based on the use of validated instruments. The modern staged repair (MRSE) in different variations, the complete primary reconstruction of exstrophy (CPRE), and the radical soft-tissue mobilization (RSTM) had been the most extensively studied and reported procedures. These major concepts are obligatory stable now for more than 20 years. Nevertheless, there are still a lot of open-ended questions e.g., on the potential for development of the bladder template, on continence, on long-term orthopedic outcome, on sexuality and fertility and on quality of life. Management of BE remains difficult and controversial. Further, clinical research should focus on multi-institutional collaborative trials to determine the optimal approach.

Keywords: bladder exstrophy, epispadias, urologic surgical procedures, delayed closure, osteotomy

\section{INTRODUCTION}

Today the diagnosis of bladder exstrophy (BE) is usually made by prenatal ultrasound screening or by inspection after birth. In classic BE the bladder is completely opened in the lower abdomen so the edge of the inner surface of the bladder is fused to the abdominal skin. The evaginated bladder template is of different individual size. The mucosa of the bladder appears reddish and polyps may be seen on it. The symphysis is widely separated. In male an epispadic urethral plate covers the whole dorsum of the penis from the bladder template to the glanular grove (1). In females, the clitoris is split and is located next to the open urethral plate. The vaginal opening appears narrow and is placed anteriorly on the perineum (1).

Often pediatricians are consulted to assess the neonates, to initiate further diagnostics and to refer them to pediatric surgeons or pediatric urologists. Due to the very low prevalence 
and various treatment approaches of this disorder, most physicians are not familiar with a standardized procedure.

The aim of BE repair is successful bladder closure and penile reconstruction in order to provide a capacious low-pressure and competent functioning reservoir as well as a good cosmetic appearance of the genitalia with unimpaired function and unobstructed urethra. By a successful primary closure normal renal function should be preserved.

The management of BE remains one of the greatest challenges in pediatric urology. While it is universally agreed that successful and gentle initial bladder closure is of utmost importance for development of bladder capacity and continence there are still numerous different concepts for the initial management of this condition (2). The main issues discussed are the time of primary closure (immediate vs. delayed closure), the type of BE repair (complete or staged), and finally the need of symphysis approximation with or without pelvic osteotomy.

Beyond doubt irrespective of the kind of reconstruction technique worldwide attempts are made to reduce the morbidity of management concepts.

\section{TIMING}

Regardless of the different surgical techniques, timing of primary closure still remains a matter of debate. The initial closure may be performed within the first $48-72 \mathrm{~h}$ of life (immediate) or at $\sim 6-12$ weeks of age (delayed).

Early closure is recommended to prevent environmental injury of the bladder mucosa (3). However, the impact of early closure in respect of the incidence of inflammation, fibrosis, or even malignant changes remains unclear. Rösch et al. characterized the histology of polyps and mucosal biopsies excised during primary delayed surgery (4) and compared their findings with previous data concerning biopsies obtained during early closure in the neonate. In comparison to the specimens of newborns with $\mathrm{BE}$ (5) active inflammation was more common but fibrosis and more severe inflammation was not more frequent in delayed closure. Ferrara et al. suggested that some microscopic changes, such as squamous metaplasia, reverse to normal after bladder closure $(6,7)$. Literature on mucosal changes in early life in $\mathrm{BE}$ is rare. Including data of subsequent series $(8,9)$, there is no advice for histologically or immunohistochemically detectable premalignant changes after the interim of 6-8 weeks and in comparison to early bladder closure neither fibrosis nor more severe inflammation seems to be more frequent after that time.

Anesthesia and analgesia are challenging in primary $\mathrm{BE}$ repair especially in early closure. Some factors associated with perioperative cardiac arrest have been identified $(10,11)$. It was found that the largest number of perioperative complications occurred in newborns $(10,12)$. Further, on there is a higher oxygen uptake rate in newborns. This means a severely increased risk of hypoxia damage in cases of circulation or ventilation problem during surgery or post-operatively. One of the most important determinants of successful bladder closure is effective local analgesia. There is evidence that neonates exposed to extreme stress during delivery, or to a surgical procedure, react to later noxious procedures with heightened behavioral responsiveness (13). The use of continuous caudal epidural analgesia allows application of local analgesia minimizing the use of intravenous and oral opiate analgesia (14). It also helps to wean the babies from the respirator and decreases pediatric intensive care unit length of stay furthermore the minimal use of opiates may also decrease gastrointestinal motility disturbances (2). In general neonatal epidural analgesia is feasible but it is a given fact that the application of an epidural catheter in a 6-weeks old infant is more reliable.

Also with regard to the development of renal function there is a more stabilized situation after the 6th week of life (15):

- Acid-base-regulation in the neonate is characterized by a reduced threshold for bicarbonate reabsorption. There is also an inability to respond to an acid load, this improves by 4-6 weeks postnatally.

- Renal concentration capacity is reduced in the first 2 month of live.

- In the neonate glomerular filtration rate (GFR) is low and doubles in the first 2 weeks and doubles again in the following 2-3 weeks.

This immature situation of renal function in the newborn period means a high risk for long-term kidney function. Even marginal iatrogenic fluid imbalance or temporary post-renal obstruction (e.g., stent or catheter obstruction) may provoke irreversible renal impairment.

Last but not least bonding after birth is of eminent importance of developing infant's self-regulation and further interaction to mother and father $(16,17)$. In particular, separation may delay and disrupt bonding in parents. Another advantage of delaying surgery is initiating breastfeeding $(18,19)$. In addition, the time between birth and initial repair is useful to the parents to get psychological support if desired and to prepare themselves for the procedure and the lengthy recovery period following.

\section{PREOPERATIVE MANAGEMENT}

In case of delayed management, only a few diagnostic measures are required preoperatively. Besides the ultrasound of the upper urinary tracts and the hips an echocardiography is recommended, recent studies indicate that there is an increased risk of associated congenital heart failures in BE patients (20). Further diagnostics like MRI or computer tomography are not necessary. Until surgery the bladder template is covered with topical ointment compresses against inflammation and alteration of the mucosa (1). There is no need for an extended hospital stay after delivery or even stay on the intensive care unit. Antibiotic prophylaxis is not necessary and not recommended in order to avoid development of resistance or topical fungal infection.

\section{MAIN SURGICAL CONCEPTS}

Already at the beginning of the twentieth century there are first reasonable attempts to treat this defect surgically. Since the 50's 
numerous different concepts are introduced to reconstruct $\mathrm{BE}$ under functional and aesthetic aspects.

Three of them has been the most extensively studied and reported procedures.

The modern staged repair (MSRE) (21), the complete primary reconstruction of bladder exstrophy (CPRE) (22) and the radical soft tissue mobilization (RSTM) (23).

The traditional staged reconstruction popularized by Gearhart and Jeffs has been a standard approach for many years $(1,21)$. The so-called "modern staged repair" (MSRE) is currently advocated as a modification by John Gearhart. He made this three-stage concept popular worldwide $(1,24)$. The bladder template the posterior urethra and the abdominal wall are closed within the first 2 days of life and the pelvic ring is adapted. Epispadias repair follows at the age of 6-9 months. In females, genital reconstruction is mostly included in the first operative procedure. As a third step, bladder neck reconstruction and simultaneously an antireflux plasty are performed when bladder capacity reaches a minimum of $85 \mathrm{cc}$. and the child is ready for continence training (1).

An antireflux plasty is always conducted with the bladder neck reconstruction (1).

Currently multiple variations of bladder neck reconstruction within this concept are established in different parts of the world. The restriction of all the above named modifications is that they can create essentially only a kind of obstruction of the bladder neck instead of a functional continence mechanism. Moreover, obstruction is not necessary for bladder growth, quiet the contrary, initial bladder neck surgery might have negative effects on the development of a functional bladder (8).

As a sort of striking a new path Grady and Mitchell introduced the complete primary repair of bladder exstrophy (CPRE) in hope it would more closely mimic the normal anatomy and therefore physiology of the normal bladder $(22,25)$. This approach includes bladder closure and reconstruction of the penis using the penile disassembly technique. This procedure is implemented on the basic concept that the primary defect of bladder exstrophy results from on anterior herniation of the bladder. It hence appears to be necessary to treat the bladder, the bladder neck and the urethra as one entity in order to transfer them successfully and permanently into the pelvis. The penile disassembly technique is performed simultaneously with bladder neck reconstruction (26). Unfortunately in the long-term follow-up in numerous cases a bladder neck reconstruction was necessary to gain social continence (27). Further on concern is raised for the risk of future detrusor underactivity as well as erectile function due to the "unimpeded radical mobilization" of the bladder-urethral plate complex in the direction of the pelvis (25).

The radical soft tissue mobilization (RSTM) introduced by Kelly (23) may be considered as the so far most consequent concept off the classical bladder neck reconstruction. The unique aspect of this technique is the dissection especially of the pelvis and the corpora cavernosa from the ischiopubic rami including the periosteum with the attachments of the voluntary and unvoluntary sphincter muscles and the pudendal vessels and nerves (23). These muscles are used as a wrap
TABLE 1 | Wide range of continence rate of the different approaches depending on definition of continence and observation period.

\begin{tabular}{lcl}
\hline Approach & Continence rate (\%) & Literature \\
\hline \multirow{2}{*}{ MSRE } & 74 & Gearhart et al. (30) \\
& 62 & Gupta et al. (31) \\
& 22 & Dickson et al. (32) \\
CPRE & 80 & Grady et al. (22) \\
& 74 & Hammouda et al. (33) \\
& 23 & Arab et al. (27) \\
RSTM & 73 & Kelly et al. (23) \\
& 70 & Jarzebowski et al. (34) \\
& $33-67$ (female) & Cuckow et al. (35) \\
\hline $4-81$ (male) & \\
\hline
\end{tabular}

around the new created posterior pelvic urethra to work as a continence mechanism. No osteotomy is performed since RSTM allows sphincter reconstruction and abdominal wall closure without tension.

RSTM is an anatomical reconstruction of BE generally performed as part of a two-staged strategy following successful neonatal closure. Complete delayed bladder closure with RSTM is a recently published modification of this concept (6).

However, the Kelly repair remains a long and technically challenging procedure even in experienced hands with a very possible risk of ischemic damage of the erectile tissue (28). Further on, leaving the symphysis without adaptation poses a certain risk with regard to the long-term abdominal wall stability and the gynecological outcome, during pregnancy as well as in terms of early prolapse of uterus (29).

\section{CONTINENCE RESULTS}

Although there are numerous publications on $\mathrm{BE}$, most of the outcome are recorded retrospectively as single-center or singlesurgeon-studies. Different definitions observation periods, endpoints, and successful outcome, in particular the definition of "continence" and possibly further surgeries lead to quit different results (Table 1). Although first results of all approaches show a very promising high rate of continence, long-term studies that must mean at least 20 years of follow-up (36) reveal disillusioning results. This fact also seems in our experience to be more realistic. Moreover, Woodhouse et al. postulate that more than $80 \%$ of the reconstructed children can achieve continence, but there is some evidence that in $70 \%$ this is lost with time (36).

\section{EPISPADIAS REPAIR}

The following procedures are the basis to ensure a functional and cosmetically acceptable outcome (1):
- The remove of dorsal chordee
- Reconstruction of the urethra
- Glandular reconstruction
- Penile skin closure 
TABLE 2 | Outcome of symphyseal approximation with and without osteotomy.

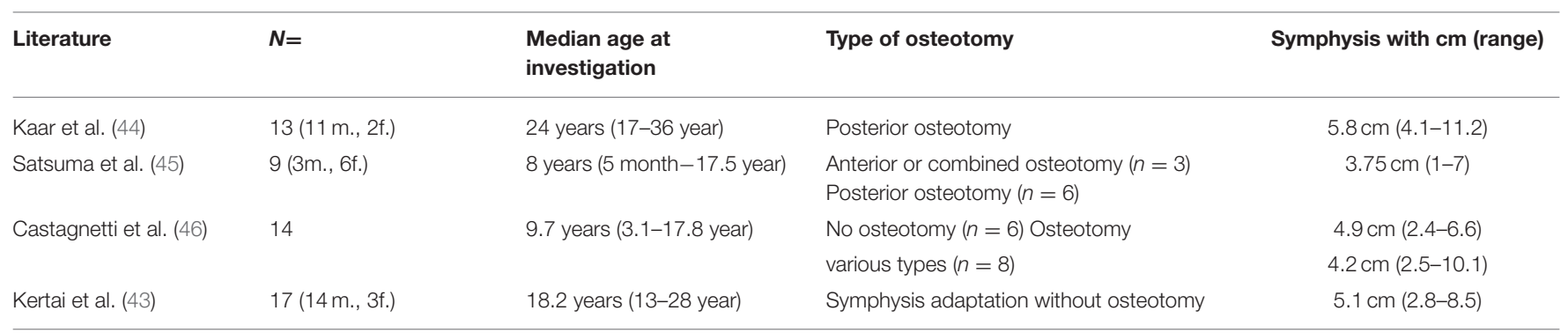

Silver was able to show that the corpora cavernosa in BE are very much shorter than in age-matched controls (37). The reduced length of the penis is thus primarily an acquired deficit of corpora cavernosa tissue and not only a consequence of the chorda and the bilateral fixation to the ascending pubic rami, which was assumed for a long time.

Ransley introduced the concept of releasing dorsal chordee by incision and dorso-medial anastomosis of the corpora cavernosa above the urethra (38). Today, the Cantwell-Ransley technique is a modification and further development in which a very much more effective relocation of the urethra between or below the corpora is possible by complete mobilization of the urethral plate from the corpora (Figure 1).

The characteristic feature of the Mitchell technique is the complete dissection of the penis into 3 parts (26): The urethral plate, the right corpus cavernosum with hemiglans and the left corpus cavernosum with hemiglans (26). After tubularization of the urethral plate, it is positioned ventrally between the corpora cavernosa. If the urethra is too short, the neomeatus hast to be positioned on the ventral part of the penis. Hence, most patients require an additional procedure for hypospadias repair. Further on concern is raised for future erectile function due to shearing and stretch injury to the nerve fibers during complete penile disassembly (25).

Perineal dissection during the RSTM allows complete exposure of the corpora cavernosa (23). Incision of the periosteum of the ischio-pubic rami until the Alcock's canal allows a full mobilization of both corpora. Mostly urethral plate is short and would retract the corpora and shorten the penis. Therefore, in most cases distal urethra is disconnected from the glans and placed in hypospadic position. After readaptation the corpora were anchored to the neosymphysis using unabsorbable sutures.

Owing to extensive mobilization, all techniques of epispadias repair have in common that they require a very meticulous dissection in the anatomical layers using magnification glass in order to maintain the blood and nerve supply of the individual structures to avoid erectile dysfunction and corporal atrophy.

Nowadays, the reconstruction of female genital becomes less invasive. The split clitoris is usually left untouched to protect the delicate nerve supply and to avoid scaring caused by later re-dehiscence of the symphysis. Recently Benz et al. were able to show that contrary to the corpora cavernosa in boys, girls with $\mathrm{BE}$ have the majority of the clitoral body anterior to the pelvic attachment (39). Skin and tissue retraction in the mons pubis area is cosmetically improved by mobilizing adjacent inguinal tissue and rotating it medially into the affected area. In about $2 / 3$ of these patients vaginoplasty is advisable (1). Episiotomy or an introitusplasty using a triangular skin-flap (Fortunoff-flap) can be performed to prevent repeated dilatations during childhood $(1,40)$. This should be done just in before or during puberty.

\section{NEED OF OSTEOTOMIES}

The role of osteotomy is still a main topic in initial bladder closure. For a long time osteotomy was regarded essential for a successful outcome. But there are also reports confirming no difference in success of bladder closure $(1,41,42)$. However, it is known that symphysis diastasis recurs after all commonly used pelvic closure techniques (43). There are only a few studies dealing with pubic diastasis after various types of pelvic osteotomy in a reasonable follow-up (36-39). According to these data the distance of recurrent mean pubic diastasis is not differing relevant in the long-term with and without osteotomy (Table 2). Castagnetti et al. compared patients after initial closure with and without osteotomy prospectively (46). In the long-term follow up they found no significant difference in the wide of pubic diastasis, in the number of exstrophy-related surgical procedures, in the incontinence rate and in the number of patients needing clean intermitting catheterization for bladder emptying (46). Kertai et al. was able to show that despite BE-specific hip morphology, long-term hip function was not impaired in adult adolescent patients after symphysial approximation without osteotomy in infancy. The symphysis diastasis after this procedure was also comparable to available post-osteotomy data in the longterm (43). In a case series published by Mushtaq et al. (2), primary bladder closure without osteotomy and post-operative immobilization was successful in 70 of 74 patients (95\%) in respect to bladder closure. In our department pelvic ring closure could be achieved during the last 15 years without osteotomy in all infants with classical BE younger than 8 weeks $(1,41)$.

In female patients symphysis approximation may prevent uterine prolapse regardless of the type pelvic adaptation (with or without osteotomy) (1).

Nevertheless, based on the available literature and contemporary variability in worldwide practice, it would appear that there is currently no consensus regarding the 


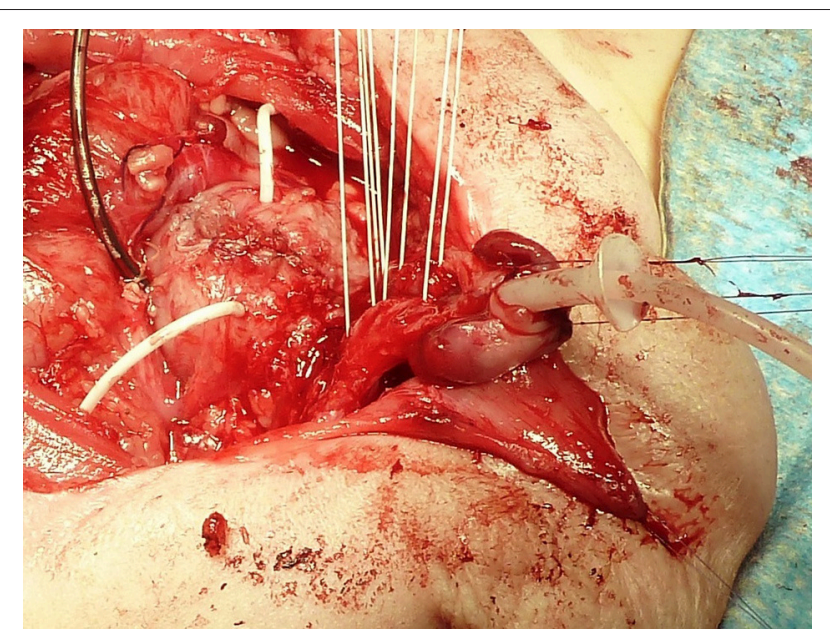

FIGURE 1 | Bladder after primary closure drained by a suprapubic and two ureteral catheters. Four sutures are prepared for approximation of the separated corpora carvernosa over the tubularized urethra with an indwelling stent. The corpora are rotated laterally to correct the dorsal deviation of the penis.

necessity of osteotomy in primary BE repair. Although not universal, most would agree on the efficacy of osteotomy in redo cases (47).

\section{CURRENT RESEARCH GAPS AND POTENTIAL FUTURE DEVELOPMENTS}

A critical look into the historical data indicates that almost nothing is new in the philosophy and treatment of BE since more than one century ago. Nevertheless, due to the benefits of new technological developments there was an appreciable progress in $\mathrm{BE}$ reconstruction during the last decades of the last century. All these major concepts are obligatory stable now for more than 20 years and ensure a safe primary bladder closure including an appealing appearance of the genitalia in experienced hands. Apart from that, there are still a lot of open ended questions e g., on the potential for development of bladder capacity, on continence, on long-term orthopedic outcome, on sexuality and fertility and on quality of life.

First of all further clinical studies should focus on multi-center prospective trials with exactly defined outcome parameters to find an optimal management (29). In addition basic research is necessary to elucidate the morphological changes in the pattern of detrusor muscle and epithelium to establish a basis for

\section{REFERENCES}

1. Ebert AK, Reutter H, Ludwig M, Rösch WH. The exstrophy-epispadias complex. Orphanet J Rare Dis. (2009) 4:23. doi: 10.1186/1750-1172-4-23

2. Mushtaq I, Gariboli M, Smeulders N, Cherian A, Desai D, Eaton S, et al. Primary bladder exstrophy closure in neonates: challenging the traditions. $J$ Urol. (2014) 191:193-8. doi: 10.1016/j.juro.2013.07.020 understanding the preconditions for development of bladderfunction and -capacity in BE.

Beside, further immuno-histologic studies of the bladder template, genetics will help to assess the prognosis in a realistic way. The systematic and comprehensive application of modern molecular genetic techniques in large BE cohorts has started to identify putative disease causing genes and regions in the genome for Mendelian and multifactorial BE phenotypes (48). Such studies can offer new diagnostics, and provide a more exact estimation of recurrence risk in affected families (48). Parallel functional analysis of the respective embryonic pathways offers a more profound understanding of the molecular mechanisms underlying the embryology of the urogenital tract (48). Moreover, understanding the respective embryonic pathways can help to explain related genitourinary malformations (49).

Tissue engineering aims to develop alternatives for current techniques in which intestinal tissue is used for patients with inadequate development of bladder capacity. Recent studies using tissue engineered extracellular matrices or acellular scaffolds with growth factor in animal models are promising $(50,51)$. However, there are scores of open issues which need to be fully clarified and defined before tissue-engineering in urology progresses from bench to bedside in BE-reconstruction.

Muscle-derived stem cells (MDSC) may offer further benefits in regenerative medicine (52). Several clinical studies have evaluated the effect of cell therapy with autologous myoblasts in the treatment of urinary incontinence, and have shown promising results $(53,54)$. Against this background MDSC therapy might represent a minimally-invasive procedure also in the treatment of patients with isolated epispadias in the near future. Latest studies are promising to generate differentiated urothelium from stem cells isolated from the urine. Urothelium obtained this way seems to be comparable with native urothelium and provides a valuable tool for reconstruction of the urinary tract as well as offers the chance for further studies in urothelial dysfunction (55).

Management of $\mathrm{BE}$ remains difficult and controversial. Further basic and clinical research should focus on multi-institutional collaborative trials to determine the optimal approach. Irrespective of that multidisciplinary ideation is in demand to generate new functional reconstruction concepts for this condition.

\section{AUTHOR CONTRIBUTIONS}

All authors contributed conception and design of the review, wrote sections of the manuscript, contributed to manuscript revision, read, and approved the submitted version.
3. Gearhart JP. Chapter 32 The bladder exstrophy-epispadias-cloacal exstrophy complex. In: Gearhart JP, Rink RC, Mouriquand PDE, editor. Pediatric Urology. Philadelphia, PA: W. B. Saunders Co; (2001). p. 511-46.

4. Rösch WH, Bertz S, Ebert AK, Hofstaedter F. Mucosal changes in the exstropic bladder: is delayed timing of reconstruction associated with premalignant changes? J Pediatr Urol. (2010) 6 (Suppl.1):555. doi: 10.1016/j.jpurol.2010.02.094 
5. Novak TE, Lakshmanan Y, Frimberger D, Epstein JI, Gearhart JP. Polyps in the exstrophic bladder. A cause of concern? J Urol. (2005) 174:1522-6 doi: 10.1097/01.ju.0000179240.25781.1b

6. Leclair MD, Faraj S, Sultan S, Audry G, Héloury Y, Kelly JH, et al. One-stage combined delayed bladder closure with Kelly radical soft-tissue mobilization in bladder exstrophy: preliminary results. J Ped Urol. (2018) 14:558-64. doi: 10.1016/j.jpurol.2018.07.013

7. Ferrara F, Dickson AP, Fishwick J, Vashisht R, Khan T, Cervellione RM. Delayed exstrophy repair (DER) does not compromise initial bladder development. J Pediatr Urol. (2014) 10:506-10. doi: 10.1016/j.jpurol.2013.10.026

8. Rubenwolf PC, Eder F, Ebert AK, Hofstaedter F, Rösch WH. Expression and potential significance of urothelial cytodifferentiation markers in the exstrophic bladder. J Urol. (2012) 187:1806-11. doi: 10.1016/j.juro.2011.12.094

9. Rubenwolf PC, Eder F, Ebert AK, Hofstaedter F, Woodhouse CR, Rösch WH. Persistent histological changes in the exstrophic bladder after primary closure-a cause of concern? J Urol. (2013) 189:671-7. doi: 10.1016/j.juro.2012.08.210

10. Morray JP, Geiduschek JM, Ramamoorthy C, Haberkern CM, Hackel A, Caplan RA, et al. Anesthesia-related cardiac arrest in children: initial findings of the Pediatric Perioperative Cardiac Arrest (POCA) Registry. Anesthesiology. (2000) 93:6-14. doi: 10.1097/00000542-200007000-00007

11. Bhananker SM, Ramamoorthy C, Geiduschek JM, Posner KL, Domino KB, Haberkern CM, et al. Anesthesia-related cardiac arrest in children: update from the pediatric perioperative cardiac arrest registry. Anesth Analg. (2007) 105:344-50. doi: 10.1213/01.ane.0000268712.00756.dd

12. Cohen MM, Cameron CB, Duncan PG. Pediatric anesthesia morbidity and mortality in the perioperative period. Anesth Analg. (1990) 70:160-7. doi: 10.1213/00000539-199002000-00005

13. Taddio A, Katz J. The effects of early pain experience in neonates on pain responses in infancy and childhood. Pediatr Drugs. (2005) 7:245-57. doi: 10.2165/00148581-200507040-00004

14. Okonkwo I, Bendon AA, Cervellione RM, Vashisht R. Continuous caudal epidural analgesia and early feeding in delayed bladder exstrophy repair: a 9-year experience. J Ped Urol. (2018) 15:76.e1-76.e8. doi: 10.1016/j.jpurol.2018.10.022

15. Wolf AS. Genes, urinary tract development and human disease. In: Gearhart JG, Rink RC, Mouriquand PDE, editors. Pediatric Urology. Philadelphia, PA: W.B. Saunders (2010). p. 172-209.

16. Bystrova $K$, Ivanova V, Edhborg M, Matthiesen AS, Ransjö-Arvidson AB, Mukhamedrakhimov R, et al. Early Contact versus separation: effects ow mother-infant interaction one year later. Birth. (2009) 36:97-109. doi: 10.1111/j.1523-536X.2009.00307.x

17. Flacking R, Lehtonen L, Thomson G, Axelin A, Ahlqvist S, Moran VH, et al. Closeness and separation in neonatal intensive care. Acta Pediatrica. (2012) 101:1032-7. doi: 10.1111/j.1651-2227.2012.02787.x

18. American Academy of Pediatrics. Breastfeeding and the use of human milk. Pediatrics. (2012) 129:e 827-41 doi: 10.1542/peds.2011-3552

19. Horta BL, Victora CG. Long-Term Effects of Breastfeeding-a Systematic Review. Geneva: WHO. WHO Library Cataloguing-in-Publication Data (2013). Avaliable online at: https://apps.who.int/iris/bitstream/10665/79198/ 1/9789241505307eng.pdf

20. Ebert AK, Zwink N, Jenetzky E, Stein R, Boemers TM, Lacher M, et al. Association between exstrophy-epispadias complex and congenital anomalies: a german multicenter study. Urology. (2018) 123:210-20. doi: 10.1016/j.urology.2018.05.039

21. Gearhart JP, Jeffs RD. State-of-the-art reconstructive surgery for bladder exstrophy at the Johns Hopkins Hospital. Am J Dis Child. (1989) 143:1475-8.

22. Grady RW, Mitchell ME. Complete primary repair of exstrophy. J Urol. (1999) 162:1415-142. doi: 10.1016/S0022-5347(05)68327-9

23. Kelly JH. Vesical exstrophy: repair using radical mobilisation of soft tissues. Pediatr Surg Int. (1995) 10:298-304. doi: 10.1007/ BF00182207

24. Baird AD, Nelson CP, Gearhart JP. Modern stage repair of bladder exstrophy: a contemporary series. J Pediatr Urol. (2007) 3:311-5. doi: 10.1016/j.jpurol.2006.09.009
25. Mesrobian HG. Complete primary repair of bladder exstrophy is associated with detrusor underactivity type of neurogenic bladder. Urology. (2014) 83:1139-44. doi: 10.1016/j.urology.2013.11.010

26. Mitchell ME, Bägli DJ. Complete penile disassembly for epispadias repair: the Mitchell technique. J Urol. (1996) 155:300-4.

27. Arab HO, Helmy TE, Abdelhalim A, Soltan M, Dawaba ME, Hafez AT Complete primary repair of bladder exstrophy: critical analysis of the longterm outcome. Urology. (2018) 117:131-6. doi: 10.1016/j.urology.2018.03.044

28. Todd Purves, Gearhart JP. Complications of radical soft-tissue mobilization procedure as a primary closure of exstrophy. J Ped Urol. (2007) 4:65-9. doi: 10.1016/j.jpurol.2007.02.006

29. Rösch WH. Commentary to 'One-stage combined delayed bladder closure with Kelly radical soft-tissue mobilization in bladder exstrophy: preliminary results'. J Pediatr Urol. (2018) 14:565. doi: 10.1016/j.jpurol.2018.09.006

30. Gearhart JP, Mathews RI. Exstrophy-epispadias complex. In: Wein AJ, Kavoussi LR, Novick AC, Partin AW, Peters CA, editors. Campbell-Walsh Urology, Vol. 4. 10th edn. Philadelphia, PA: Elsevier (2012). p. 3325-78.

31. Gupta AD, Goel SK, Woodhouse CR, Wood D. Examining long-term outcomes of bladder exstrophy: a 20-year follow-up. BJU Int. (2014) 113:13741. doi: 10.1111/bju.12389

32. Dickson AP. The management of bladder exstrophy: the Manchester experience. J Pediatr Surg. (2014) 49:244-50. doi: 10.1016/j.jpedsurg.2013.11.031

33. Hammouda HM, Kotb H. Complete primary repair of bladder exstrophy: initial experience with 33 cases. J Urol. (2004) 172(4 Pt. 1):1441-4; discussion 1444. doi: 10.1097/01.ju.0000139190.77295.cb

34. Jarzebowski AC, McMullin ND, Grover SR, Southwell BR, Hutson JM. The Kelly technique of bladder exstrophy repair: continence, cosmesis and pelvic organ prolapse outcomes. J Urol. (2009)182 (4 Suppl):1802-6. doi: 10.1016/j.juro.2009.02.083

35. Cuckow PM, Cao KX. Meeting the challenges of reconstructive urology - Where are we now? J Pediatr Surg. (2018) 54:223-8. doi: 10.1016/j.jpedsurg.2018.10.070.6

36. Woodhouse CR, North AC, Gearhart JP. Standing the test of time: long-term outcome of reconstruction of the exstrophy bladder. World J Urol. (2006) 24:244-9. doi: 10.1007/s00345-006-0053-7

37. Silver RI, Yang A, Ben-Chaim J, Jeffs RD, Gearhart JP. Penile length in adulthood after exstrophy reconstruction. J Urol. (1997) 157:999-1003. doi: 10.1016/S0022-5347(01)65131-0

38. Gearhart JP, Leonard MP, Burgers JK, Jeffs RD. The CantwellRansley technique for repair of epispadias. J Urol. (1992) 148:851-4. doi: 10.1016/S0022-5347(17)36742-3

39. Benz KS, Dunn E, Solaiyappan M, Maruf M, Kasprenski M, Jayman J, et al. Novel observations of female genital anatomy in classic bladder exstrophy using 3-dimensional magnetic resonance imaging reconstruction. J Urol. (2018) 200:882-9. doi: 10.1016/j.juro.2018.04.071

40. Fortunoff S, Lattimer JK, Edson M. Vaginoplasty technique for female pseudohermaphrodites. Surg Gynecol Obstet. (1964) 118:545-8.

41. Rösch WH, Promm M. Blasenekstrophie: qualität der primärversorgung und langzeitprognose. Urologe. (2016) 55:53-7. doi: 10.1007/s00120-015-0010-4

42. Husman DA, McLorie GA, Churchill BM. Closure of the exstrophic bladder: an evaluation of the factors leading to its success and its importance on urinary incontinence. J Urol. (1989) 142:522-4. doi: 10.1016/S0022-5347(17)38803-1

43. Kertai MA, Rösch WH, Brandl R, Hirschfelder H, Zwink N, Ebert AK. Morphological and Functional Hip long-term results after exstrophy repair. Eur J Pediatr Surg. (2016) 26:508-13. doi: 10.1055/s-0035-1564711

44. Kaar SG, Cooperman DR, Blakemore IC, Thompson GH, Petersilge CA, Elder JS, et al. Association of bladder exstrophy with congenital pathology of the hip and the lumbosacral spine: a long-term follow-up study of 13 patients. $J$ Pediatr Orthop. (2002) 22:62-6. doi: 10.1097/01241398-200201000-00014

45. Satsuma S, Koboyashi D, Yoshiya S, Kurosaka M. Comparison of posterior and anterior pelvic osteotomy for bladder exstrophy complex. J Pediatr Orthop B. (2006) 15:141-6. doi: 10.1097/01.bpb.0000191873.61635.10

46. Castagnetti M, Gigante C, Perrone G, Rigamonti W. Comparison of musculoskeletal and urological functional outcomes in patients with bladder exstrophy undergoing repair with and without osteotomy. Pediatr Surg Int. (2008) 24:689-93. doi: 10.1007/s00383-008-2132-x 
47. Borer JG. Are osteotomies necessary for bladder exstrophy closure? J Urol. (2014) 191:13-4. doi: 10.1016/j.juro.2013.10.048

48. Reutter H, Keppler-Noreuil K, Keegan CE, Thiele H, Yamada G, Ludwig M. Genetics of Bladder-Exstrophy-Epispadias Complex (BEEC): systematic elucidation of mendelian and multifactorial phenotypes. Curr Genomics. (2016) 17:4-13. doi: 10.2174/1389202916666151014221806

49. Zhang R, Knapp M, Suzuki K, Kajioka D, Schmidt JM, Winkler J, et al. ISL1 is a major susceptibility gene for classic bladder exstrophy and a regulator of urinary tract development. Sci Rep. (2017) 7:42170. doi: 10.1038/ srep42170

50. Davis NF, Cunnane EM, O'Brien FJ, Mulvihill JJ, Walsh MT. Tissue engineered extracellular matrices (ECMs) in urology: evolution and future directions. Surgeon. (2018) 16:55-65. doi: 10.1016/j.surge.2017.07.002

51. Roelofs LAJ, de Jonge PKJD, Oosterwijk E, Tiemessen DM, Kortmann BBM, de Gier RPE, et al. Bladder regeneration using multiple acellular scaffolds with growth factors in a bladder. Tissue Eng Part A. (2018) 24:11-20. doi: 10.1089/ten.tea.2016.0356

52. Zhang L, Wang W. Research progress in muscle-derived stem cells: literature retrieval results based on international database. Neural Regen Res. (2012) 7:784-91. doi: 10.3969/j.issn.1673-5374.2012.10.010

53. Carr LK, Robert M, Kultgen PL, Herschorn S, Birch C, Murphy $\mathrm{M}$, et al. Autologous muscle derived cell therapy for stress urinary incontinence: a prospective, dose ranging study. J Urol. (2013) 189:595-601. doi: $10.1016 /$ j.juro.2012.09.028

54. Sharifiaghdas F, Tajalli F, Taheri M, Naji M, Moghadasali R, Aghdami $\mathrm{N}$, et al. Effect of autologous muscle-derived cells in the treatment of urinary incontinence in female patients with intrinsic sphincter deficiency and epispadias: a prospective study. Int J Urol. (2016) 23:581-6. doi: $10.1111 /$ iju.13097

55. Wan Q, Xiong G, Liu G, Shupe TD, Wei G, Zhang D, et al. Urothelium with barrier function differentiated from human urine-derived stem cells for potential use in urinary tract reconstruction. Stem Cell Res Ther. (2018) 9:304. doi: 10.1186/s13287-018-1035-6

Conflict of Interest Statement: The authors declare that the research was conducted in the absence of any commercial or financial relationships that could be construed as a potential conflict of interest.

Copyright $\odot 2019$ Promm and Roesch. This is an open-access article distributed under the terms of the Creative Commons Attribution License (CC BY). The use, distribution or reproduction in other forums is permitted, provided the original author(s) and the copyright owner(s) are credited and that the original publication in this journal is cited, in accordance with accepted academic practice. No use, distribution or reproduction is permitted which does not comply with these terms. 